\title{
Effectiveness of iStent Trabecular Microbypass System Combined with Phacoemulsification versus Phacoemulsification Alone in Patients with Glaucoma and Cataract Depending on the Initial Intraocular Pressure
}

\author{
Milena Kozera $^{\mathrm{a}} \quad$ Joanna Konopińskab ${ }^{\mathrm{b}}$ Zofia Mariak $^{\mathrm{b}}$ Marek Rękas $^{\mathrm{a}}$ \\ aDepartment of Ophthalmology, Military Institute of Medicine, Warsaw, Poland; bepartment of Ophthalmology, \\ Medical University of Białystok, Białystok, Poland
}

\section{Keywords}

iStent · Trabecular microbypass stent · Glaucoma ·

Microinvasive glaucoma surgery

\begin{abstract}
Introduction: To assess the effect of iStent trabecular microbypass implantation combined with phacoemulsification on intraocular pressure (IOP) and glaucoma medications and to compare this to outcomes of phacoemulsification alone in patients with mild to moderate primary open-angle glaucoma (POAG) depending on initial IOP. Materials and Methods: Eighty subjects with cataract and POAG were randomized 1:1 into either iStent implantation and cataract surgery (iStent group) $(n=44)$ or cataract surgery alone (control group) $(n=36)$. Groups were divided according to initial IOP (after washout period) into IOP $<26 \mathrm{~mm}$ $\mathrm{Hg}$ and IOP $\geq 26 \mathrm{~mm} \mathrm{Hg}$. Patients were assessed preoperatively and at postoperative day 1, week 1, and months 1, 3, 6,12 , and 24 . Outcome measures included best-corrected visual acuity, IOP, and glaucoma medications. Results: Postoperatively at 24 months, mean IOP decreased from $20.93 \pm$ 1.28 to $17.79 \pm 2.50 \mathrm{~mm} \mathrm{Hg}$ in the IOP subgroup $<26 \mathrm{~mm} \mathrm{Hg}$ and from $26.00 \pm 0.00$ to $19.86 \pm 2.19$ in the subgroup $\geq 26$
\end{abstract}

$\mathrm{mm} \mathrm{Hg}$ in the control group. In the iStent group $<26 \mathrm{~mm} \mathrm{Hg}$, IOP decreased from $22.04 \pm 1.64$ to $15.57 \pm 2.13 \mathrm{~mm} \mathrm{Hg}$ and from $26.6 \pm 1.09$ to $17.06 \pm 2.43 \mathrm{~mm} \mathrm{Hg}$ in the iStent group $\geq 26 \mathrm{~mm} \mathrm{Hg}$. Conclusion: In patients with open-angle glaucoma and cataract, iStent implantation combined with cataract surgery reduced IOP significantly through 2 years, with greater reductions achieved versus phacoemulsification alone. In patients with baseline IOP $<26 \mathrm{~mm} \mathrm{Hg}$, surgery reduced IOP and medication use significantly declined through 2 years, with greater reductions achieved versus patients with baseline IOP $\geq 26 \mathrm{~mm} \mathrm{Hg}$. The study was registered at ClinicalTrials.gov under the number NCT03807869.

(c) 2020 S. Karger AG, Basel

\section{Introduction}

Trabeculectomy has been the gold standard in glaucoma surgery for years. However, due to the risk of vision-threatening complications, as well as a decrease in its effectiveness over time after surgery $[1,2]$, the search for safer surgical techniques is continually underway. For over 10 years, intensive research has been conducted on the use of low-invasive glaucoma surgery methods, which karger@karger.com

www.karger.com/ore

Karger ${ }^{\prime}=$
(C) 2020 S. Karger AG, Basel

Pedicine

PL-04-141 Warsaw (Poland)

m.kozera@onet.eu 
have been termed microinvasive glaucoma surgery (MIGS). Among the MIGS, different anatomical categories are distinguished, and one of them is procedures on the Schlemm's canal (SC) because underlying the intraocular pressure (IOP) growth mechanism is most likely the increased resistance of aqueous humor outflow at the level of its internal wall $[3,4]$. Researchers have also pointed out that episcleral veins of inheritance also have their role in the mechanism. Collector channels (CC) and epidural veins (EV) are responsible for as much as $50 \%$ of aqueous humor perfusion [5].

This MIGS category includes the Glaukos iStent microstent (Glaukos Corporation, Laguna Hills, CA, USA), which consists of a single part and is made of heparincoated titanium. It is implanted directly into the SC using a special feeder, creating a bypass that improves the outflow of liquid directly to the SC and CC [6].

Battista et al. [7] examined anatomical changes in SC and CC in bovine eyes by increasing the level of IOP in the eyes in the range of 7-45 $\mathrm{mm} \mathrm{Hg}$. He showed that under conditions of high pressure, the possibilities for effective drainage of aqueous humor were doubled [7]. Increased pressure caused Schlemm's channel to collapse progressively toward water collectors, and this blocked the drain in individual sections. At IOP level above 30 $\mathrm{mm} \mathrm{Hg}$, as much as $95 \%$ of collectors were blocked. In addition, in response to an increased IOP in the eyes with primary open-angle glaucoma (POAG), the SC surface was reduced, which was caused by the depression of its inner wall in the CC holes [5]. These results are also confirmed by histopathological studies, which show significant collapse and narrowing of CC and EV, with adhesion of the inner wall of the SC and entanglement of the trabecular to the CC entrances [8]. Based on the above studies, it can be hypothesized that in patients whose IOP values exceed 25-30 mm Hg, most CC are probably closed and SC is collapsed.

Many prospective, multicenter clinical trials have shown that microbypass iStent safely and effectively reduces IOP while reducing or eliminating the need for antihypertensive drugs in patients with POAG [9-12]. However, according to the assumed Battista laboratory model, the effectiveness of iStent will be limited at an output IOP of $\geq 26 \mathrm{~mm} \mathrm{Hg}$ due to the collapse of distal aqueous humor outflow tracts.

We decided to conduct a study that would show how effective iStent is when used as a treatment option in the group of patients with IOP $<26 \mathrm{~mm} \mathrm{Hg}$ compared to IOP $\geq 26 \mathrm{~mm} \mathrm{Hg}$. As we already know cataract removal alone causes a decrease in IOP, so as a control group we decid- ed to select a group of patients only subjected to phacoemulsification to exclude this component of antihypertensive effect. The study was registered on clinicaltrials. gov under the number NCT03807869.

\section{Methods}

\section{Recruitment}

This prospective, randomized, single-center trial enrolled 80 eyes of 57 patients aged 21 years or older who suffered from POAG and were otherwise healthy. The trial protocol was conducted in accordance with the tenets of the Helsinki Declaration and was approved by the Bioethics Committee at the Military Institute of Medicine (Nr 16/WIM/2013). Written legally binding, conscious informed consent was obtained from every patient prior to their recruitment in the trial. Inclusion criteria required patients to have at least 1 eye diagnosed with mild to moderate POAG as well as age-related cataract, treated with 1-4 ocular hypotensive medications and no prior glaucoma incisional or laser surgery. Characteristics of glaucoma included typical glaucomatous changes of the optic nerve observed via ophthalmoscopy, cup to disk ratio (C/D) $\leq 0.9$, and characteristic glaucomatous visual field loss, defined as mean deviation (MD) 0 to $-6.0 \mathrm{~dB}$ (mild glaucoma) and $\mathrm{MD}$ from -6.01 to $-12.00 \mathrm{~dB}$ (moderate glaucoma) confirmed by a Humphrey visual field analyzer (Carl Zeiss AG, Germany) with the SITA Standard 24-2 algorithm. In order to be randomized, IOP in the study eye needed to be $\leq 25 \mathrm{~mm} \mathrm{Hg}$ on medication(s). The IOP result was based on a diurnal assessment (i.e., 3 averaged standardized measurements using Goldmann tonometry over the course of 1 day) in the eye qualified for surgical treatment. If both eyes of a patient were eligible, the eye with more advanced cataract and/or optic nerve damage was selected as the first eye to be included, with the second eye additionally included in the study after the first eye had been treated, if the patient agreed. Visual acuity no worse than 20/200 tested on Snellen charts in either eye was required. The anterior chamber angle was required to be open in all 4 quadrants.

Patients with glaucoma other than POAG were excluded. Other exclusion criteria respected evidence of severe eye disease, including proliferative diabetic retinopathy, corneal diseases (e.g., Fuchs dystrophy), dry and exudative age-related macular degeneration, narrow angles, prior glaucoma surgical interventions (trabeculoplasty, trabeculectomy, filtration procedures, and cycloablation), and prior ocular surgical procedures unrelated to glaucoma and cataract, with the exception of oculoplastic procedures; visual field $\mathrm{MD}$ worse than $-12.00 \mathrm{~dB}$ confirmed by a Humphrey analyzer; and use of $>4$ ocular hypotensive medications. Patients enrolled to the study had discontinued medications from the eye qualified for the procedure. In the case of prostaglandins and $\beta$-blockers, this period lasted 4 weeks and for alpha-adrenergic drugs and carbonic anhydrase inhibitors, 2 weeks. After the washout period, they were assigned to IOP $<26 \mathrm{~mm} \mathrm{Hg}$ and IOP $\geq 26$ mm Hg subgroups.

A computer-generated randomization list was created for this study, with allocation concealment implementation. Randomization was performed using sealed envelopes, opened on the day of surgery, to determine the randomization group. Eyes were individually randomized in a 1:1 ratio to either the iStent combined with phacoemulsification or phacoemulsification alone group. 
Table 1. Preoperative characteristics

\begin{tabular}{|c|c|c|c|c|}
\hline & \multicolumn{2}{|l|}{ iStent, $n=44$} & \multicolumn{2}{|l|}{ Control, $n=36$} \\
\hline & $\begin{array}{l}\mathrm{IOP}<26 \mathrm{~mm} \mathrm{Hg} \\
(n=28)\end{array}$ & $\begin{array}{l}\mathrm{IOP} \geq 26 \mathrm{~mm} \mathrm{Hg} \\
(n=16)\end{array}$ & $\begin{array}{l}\text { IOP }<26 \mathrm{~mm} \mathrm{Hg} \\
(n=29)\end{array}$ & $\begin{array}{l}\mathrm{IOP} \geq 26 \mathrm{~mm} \mathrm{Hg} \\
(n=7)\end{array}$ \\
\hline \multicolumn{5}{|l|}{ Age } \\
\hline Mean (SD) & $70.1(8.5)$ & $72.3(6.4)$ & $71.4(6.6)$ & $73.6(7.1)$ \\
\hline Range & $54-84$ & $56-82$ & $59-83$ & $60-81$ \\
\hline \multicolumn{5}{|l|}{ Eye, $n$} \\
\hline $\mathrm{OD} / \mathrm{OS}$ & $12 / 16$ & $7 / 9$ & $17 / 9$ & $4 / 3$ \\
\hline \multicolumn{5}{|l|}{ Gender, $n$} \\
\hline Male/female & $8 / 18$ & $6 / 10$ & $6 / 23$ & $2 / 5$ \\
\hline \multicolumn{5}{|l|}{ BCVA (logMAR converted score) } \\
\hline Mean (SD) & $0.49(0.22)$ & $0.68(0.21)$ & $0.52(0.23)$ & $0.58(0.14)$ \\
\hline \multicolumn{5}{|l|}{$C D R$} \\
\hline Mean (SD) & $0.6(0.2)$ & $0.7(0.3)$ & $0.6(0.2)$ & $0.5(0.1)$ \\
\hline \multicolumn{5}{|l|}{ Prior glaucoma surgery } \\
\hline $\begin{array}{l}\text { Visual field } M D, d B \\
\text { Mean (SD) }\end{array}$ & \multicolumn{3}{|c|}{ Visual field $M D, d B$} & $-4.1(2.8)$ \\
\hline \multicolumn{5}{|l|}{ Washout IOP, $\mathrm{mm} \mathrm{Hg}$} \\
\hline \multicolumn{5}{|l|}{ Medication burden } \\
\hline
\end{tabular}

IOP, intraocular pressure; BCVA, best-corrected visual acuity; MD, mean deviation.

\section{Surgical Technique}

All surgeries were carried out at a single center (Department of Ophthalmology, Military Medical Institute in Warsaw) by 1 surgeon (M.R.). The surgical technique was performed under local retrobulbar anesthesia with $2 \%$ Xylocaine. All patients underwent standard cataract phacoemulsification with implantation of an artificial posterior-chamber IOL. If randomized to the iStent group, patients underwent iStent implantation after successful IOL insertion into the bag. The detail of the iStent implantation technique and the iStent device has been described in detail before [13]. A single iStent was inserted through the existing temporal incision in the corneal limbus into the nasal quadrant of SC, ab interno, using a Swan-Jacobs gonioscope. The injector was retracted after the stent's position was checked. The appearance of a small blood reflux, of a self-limiting character, signified proper placement of the iStent. Removal of viscoelastic and sealing of the anterior chamber with physiological salt solution, in order to obtain physiological pressure, concluded the operation. Eyes were treated postoperatively with topical-containing steroids (loteprednol) 3 times daily for 4 weeks (which then were tapered to BID for a week), antibiotic (Moxifloksacinum) 3 times daily for 2 weeks, and nonsteroidal anti-inflammatory drugs (NSAIDs) 3 times daily for 4 weeks. Patients were followed up postoperatively through day 1 , week 1 , and months $1,3,6,12$, and 24 .

iStent versus Cataract Surgery Depending on IOP

\section{Study Procedures}

Preoperative study examinations in addition to standard care involved best-corrected visual acuity (BCVA) on Snellen charts, slitlamp test examination of the anterior and posterior segments, diurnal IOP, ultrasound pachymetry, and gonioscopy. Diurnal IOP was measured using Goldmann tonometry with the final value the average of readings taken thrice during the day. Perimetry was performed using a Humphrey visual field analyzer, SITA Standard 24-2 algorithm.

Postoperatively, BCVA was evaluated using Snellen charts. IOP was assessed using Goldmann applanation tonometry, medication burden was assessed, and the anterior segment and fundus were examined. Additionally, gonioscopic evaluation of the angle was also conducted (except on postoperative day 1). Humphrey SITA Standard 24-2 visual field tests were performed at months 12 and 24. Trial-related adverse events were collected at each visit to establish the safety profile.

\section{Outcome Measures}

IOP values were used as the primary outcome measure. Secondary outcome measures included medication burden with regard to the number of medications taken pre- and postoperatively and the safety profile. Safety outcomes were measured by BCVA outcomes, intra- and postoperative complications, and observed trial-related adverse events. 
Table 2. IOP mean values, median values, standard deviations, and range at specific times after surgery in the iStent group

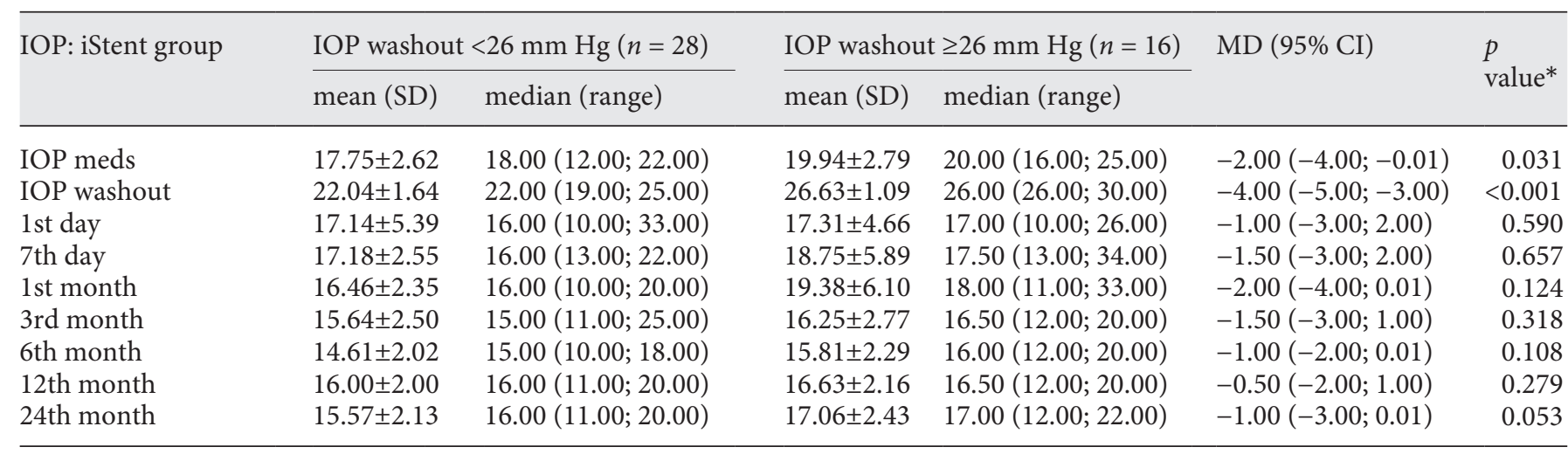

IOP, intraocular pressure; MD, mean deviation. * Mann-Whitney U test; MD, difference in medians calculated as IOP washout $<26$ group minus IOP washout $\geq 26$ group with $95 \%$ confidence interval.

\section{Statistical Analysis}

Statistical analysis was performed using the R program, version 3.5.1. The studied variables were presented using descriptive statistics. Nominal variables were compared between groups using the $\chi^{2}$ test or Fisher's exact test when the number of cells did not allow the use of the $\chi^{2}$ test. The normality of the distribution of quantitative variables was assessed using the Shapiro-Wilk test, skewness and kurtosis indicators, and visual histogram evaluation. Equality of variances was checked by Leven's test. The comparison of groups was performed using the Mann-Whitney U test due to the failure to meet the parametric test assumptions. The significance level $\alpha=0.05$ was used, and all tests were 2 -sided.

\section{Results}

\section{Demographic Data}

Eighty eyes (of 57 patients) all with a diagnosis of POAG and coexisting cataract without any prior glaucoma surgery were included into the trial. Twenty-three patients had bilateral sequential cataract surgery, with each eye randomized separately. Preoperative washout IOP was $22.04 \pm 1.64 \mathrm{~mm} \mathrm{Hg}$ in the iStent group $<26 \mathrm{~mm}$ $\mathrm{Hg}$ and $26.6 \pm 1.09 \mathrm{~mm} \mathrm{Hg}$ in the iStent washout $\geq 26 \mathrm{~mm}$ $\mathrm{Hg}$ group. In the control group with initial washout IOP $<26 \mathrm{~mm} \mathrm{Hg}$, IOP was $20.93 \pm 1.28$, and it was $26.00 \pm 0.00$ $\mathrm{mm} \mathrm{Hg}$ in the control group $\geq 26 \mathrm{~mm} \mathrm{Hg}$ (no statistic differences between iStent and control groups were found at the beginning of the study, $p=0.28$ ). The mean medication burden in the iStent group IOP $<26 \mathrm{~mm} \mathrm{Hg}$ was 1.32 \pm 0.55 and at $\mathrm{IOP} \geq 26 \mathrm{~mm} \mathrm{Hg}, 2.50 \pm 0.89$. In the control group, the number of antiglaucoma medications was 1.03 \pm 0.19 and $1.86 \pm 0.69$, respectively. Mean follow-up time was 24.6 months (range 24-36 months) (Table 1).

\section{Intraocular Pressure}

For the iStent group, the IOP level differed significantly between both groups (IOP washout $\geq 26 \mathrm{~mm} \mathrm{Hg}$ and IOP washout $<26 \mathrm{~mm} \mathrm{Hg}$ ) only before surgery. For the entire postoperative period, both groups of patients did not differ significantly in terms of the average level of IOP (Table 2). The mean IOP level after surgery was significantly higher in patients from the IOP washout control group $\geq 26 \mathrm{~mm} \mathrm{Hg}$ compared to patients with IOP washout $<26 \mathrm{~mm} \mathrm{Hg}$ for each observation period except for months 3 and 24, as shown in Table 3.

Comparing the percentage decreases in IOP in the iStent IOP group $<26 \mathrm{~mm} \mathrm{Hg}$ and in the IOP control group $<26 \mathrm{~mm} \mathrm{Hg}$ by $>50,>40,>30$, and $>20 \%$, respectively, to the size before surgery, a significantly higher percentage of patients were found with a decrease in IOP by $\geq 20 \%$ in the iStent group $<26 \mathrm{~mm} \mathrm{Hg}$ than in the control group $<26 \mathrm{~mm} \mathrm{Hg}$ within 24 months after surgery ( 82.1 vs. $51.7 \%$, respectively, $p=0.024$ ) (Table 4 ). Analyzing the percentage of decrease in IOP in the iStent IOP group $\geq 26 \mathrm{~mm} \mathrm{Hg}$ and in the IOP control group $\geq 26 \mathrm{~mm}$ $\mathrm{Hg}$ by $>50,>40,>30$, and $>20 \%$, respectively, in relation to the size before surgery, no statistically significant differences were observed between the groups in the course of the whole observation period (Table 5).

\section{Medication Burden}

Patients from the iStent IOP $<26 \mathrm{~mm} \mathrm{Hg}$ group received on average $1.32 \pm 0.55$ drugs before surgery, and 24 months after surgery, the number of drugs dropped to $0.32 \pm 0.55$. For patients in the iStent IOP group $\geq 26 \mathrm{~mm}$ $\mathrm{Hg}$, it was $2.50 \pm 0.89$ before surgery and $0.88 \pm 1.26$, re- 
Table 3. IOP mean values, median values, standard deviations, and range at specific times after surgery in the control group

\begin{tabular}{|c|c|c|c|c|c|c|}
\hline \multirow{2}{*}{$\begin{array}{l}\text { IOP control } \\
\text { group }\end{array}$} & \multicolumn{2}{|c|}{ IOP washout $<26 \mathrm{~mm} \mathrm{Hg}(n=29)$} & \multicolumn{2}{|c|}{ IOP washout $\geq 26 \mathrm{~mm} \mathrm{Hg}(n=7)$} & \multirow[t]{2}{*}{$\mathrm{MD}(95 \% \mathrm{CI})$} & \multirow{2}{*}{$\begin{array}{l}p \\
\text { value* }^{*}\end{array}$} \\
\hline & mean $(\mathrm{SD})$ & median (range) & mean $(\mathrm{SD})$ & median (range) & & \\
\hline IOP washout & $20.93 \pm 1.28$ & $21.00(19.00 ; 24.00)$ & $26.00 \pm 0.00$ & $26.00(26.00 ; 26.00)$ & $-5.00(-6.00 ;-5.00)$ & $<0.001$ \\
\hline 1st day & $16.72 \pm 2.99$ & $16.00(9.00 ; 22.00)$ & $22.14 \pm 6.26$ & $19.00(16.00 ; 32.00)$ & $-3.00(-10.00 ;-1.00)$ & 0.022 \\
\hline 7th day & $16.03 \pm 3.06$ & $16.00(10.00 ; 22.00)$ & $19.86 \pm 4.45$ & $20.00(15.00 ; 29.00)$ & $-4.00(-6.00 ;-1.00)$ & 0.024 \\
\hline 6th month & $16.28 \pm 2.52$ & $17.00(12.00 ; 23.00)$ & $18.14 \pm 1.95$ & $19.00(14.00 ; 20.00)$ & $-2.00(-4.00 ;-0.01)$ & 0.024 \\
\hline 12th month & $16.41 \pm 1.97$ & $17.00(12.00 ; 19.00)$ & $19.43 \pm 3.51$ & $19.00(16.00 ; 27.00)$ & $-2.00(-4.00 ;-0.01)$ & 0.011 \\
\hline 24th month & $16.79 \pm 2.50$ & $17.00(12.00 ; 22.00)$ & $18.86 \pm 2.19$ & $18.00(16.00 ; 23.00)$ & $-1.00(-4.00 ; 0.01)$ & 0.052 \\
\hline
\end{tabular}

IOP, intraocular pressure; MD, mean deviation. * Mann-Whitney $\mathrm{U}$ test; $\mathrm{MD}$, difference in medians calculated as IOP washout $<26$ group minus IOP washout $\geq 26$ group with $95 \%$ confidence interval.

Table 4. Proportion of eyes with IOP reduction $>50,>40,>30$, and $>20 \%$ by time points between control and iStent groups for patients with IOP washout $<26 \mathrm{~mm} \mathrm{Hg}$

\begin{tabular}{|c|c|c|c|c|}
\hline & \multicolumn{4}{|c|}{ IOP reduction versus baseline (washout) } \\
\hline & $\geq 50 \%$ & $\geq 40 \%$ & $\geq 30 \%$ & $\geq 20 \%$ \\
\hline Control $(n=29)(\%, 95 \%$ CI $)$ & $0.0(0.0 ; 11.9)$ & $3.4(0.1 ; 17.8)$ & $24.1(10.3 ; 43.5)$ & $55.2(35.7 ; 73.6)$ \\
\hline iStent $(n=28)(\%, 95 \%$ CI $)$ & $3.6(0.1 ; 18.3)$ & $7.1(0.9 ; 23.5)$ & $39.3(21.5 ; 59.4)$ & $78.6(59.0 ; 91.7)$ \\
\hline$p$ value* & 0.491 & 0.612 & 0.263 & 0.092 \\
\hline \multicolumn{5}{|l|}{24 months } \\
\hline Control $(n=29)(\%, 95 \% \mathrm{CI})$ & $0.0(0.0 ; 11.9)$ & $3.4(0.1 ; 17.8)$ & $24.1(10.3 ; 43.5)$ & $51.7(32.5 ; 70.6)$ \\
\hline iStent $(n=28)(\%, 95 \% \mathrm{CI})$ & $7.1(0.9 ; 23.5)$ & $10.7(2.3 ; 28.2)$ & $39.3(21.5 ; 59.4)$ & $82.1(63.1 ; 93.9)$ \\
\hline$p$ value* & 0.237 & 0.353 & 0.263 & 0.024 \\
\hline
\end{tabular}

Data presented as $\%$ of patients with IOP reduction of $>50,>40,>30$, and $>20 \%$ versus baseline with $95 \%$ confidence interval. IOP washout level was used as baseline level. IOP, intraocular pressure. ${ }^{*} \chi^{2}$ test or Fisher's exact test.

Table 5. Proportion of eyes with IOP reduction $>50,>40,>30$, and $>20 \%$ by time points between control and iStent groups for patients with IOP washout $\geq 26 \mathrm{~mm} \mathrm{Hg}$

\begin{tabular}{|c|c|c|c|c|}
\hline & \multicolumn{4}{|c|}{ IOP reduction versus baseline (washout) } \\
\hline & $\geq 50 \%$ & $\geq 40 \%$ & $\geq 30 \%$ & $\geq 20 \%$ \\
\hline Control $(n=7)(\%, 95 \%$ CI $)$ & $0.0(0.0 ; 40.9)$ & $0.0(0.0 ; 40.9)$ & $42.9(9.9 ; 81.6)$ & $85.7(42.1 ; 99.6)$ \\
\hline iStent $(n=16)(\%, 95 \% \mathrm{CI})$ & $6.3(0.2 ; 30.2)$ & $43.8(19.8 ; 70.1)$ & $81.3(54.4 ; 96.0)$ & $100.0(79.4 ; 100.0)$ \\
\hline$p$ value* & $>0.999$ & 0.057 & 0.137 & 0.304 \\
\hline Control $(n=7)(\%, 95 \%$ CI $)$ & $0.0(0.0 ; 40.9)$ & $0.0(0.0 ; 40.9)$ & $57.1(18.4 ; 90.1)$ & $81.7(42.1 ; 99.6)$ \\
\hline iStent $(n=16)(\%, 95 \% \mathrm{CI})$ & $6.3(0.2 ; 30.2)$ & $25.0(7.3 ; 52.4)$ & $75.0(47.6 ; 92.7)$ & $93.8(69.8 ; 99.8)$ \\
\hline$p$ value* $^{*}$ & $>0.999$ & 0.273 & 0.626 & 0.526 \\
\hline
\end{tabular}

Data presented as $\%$ of patients with IOP reduction of $>50,>40,>30$, and $>20 \%$ versus baseline with $95 \%$ confidence interval. IOP washout level was used as baseline level. IOP, intraocular pressure. ${ }^{*} \chi^{2}$ test or Fisher's exact test. 
Table 6. Amount of medications' mean values, median values, standard deviations, and range at specific times after surgery in the iStent group

\begin{tabular}{|c|c|c|c|c|c|c|}
\hline $\begin{array}{l}\text { Meds: iStent } \\
\text { group }\end{array}$ & \multicolumn{2}{|c|}{ IOP $<26(n=28)$} & \multicolumn{2}{|c|}{ IOP $\geq 26(n=16)$} & MD (95\% CI) & $p$ value* \\
\hline 1st day & $0.07 \pm 0.38$ & $0.00(0.00 ; 2.00)$ & $0.00 \pm 0.00$ & $0.00(0.00 ; 0.00)$ & $0.00(0.00 ; 0.00)$ & 0.479 \\
\hline 7th day & $0.00 \pm 0.00$ & $0.00(0.00 ; 0.00)$ & $0.44 \pm 0.81$ & $0.00(0.00 ; 2.00)$ & $0.00(-0.00007 ; 0.00)$ & 0.007 \\
\hline 1 st month & $0.00 \pm 0.00$ & $0.00(0.00 ; 0.00)$ & $0.63 \pm 0.89$ & $0.00(0.00 ; 2.00)$ & $0.00(-1.00 ; 0.00)$ & $<0.001$ \\
\hline 24th month & $0.32 \pm 0.55$ & $0.00(0.00 ; 2.00)$ & $0.88 \pm 1.26$ & $0.00(0.00 ; 4.00)$ & $0.00(-1.00 ; 0.01)$ & 0.05 \\
\hline
\end{tabular}

IOP, intraocular pressure; MD, mean deviation. * Mann-Whitney $\mathrm{U}$ test; MD, difference in medians calculated as IOP washout $<26$ group minus IOP washout $\geq 26$ group with $95 \%$ confidence interval.

Table 7. Amount of medications' mean values, median values, standard deviations, and range at specific times after surgery in the control group

\begin{tabular}{|c|c|c|c|c|c|c|}
\hline $\begin{array}{l}\text { Meds: control } \\
\text { group }\end{array}$ & \multicolumn{2}{|c|}{ IOP $<26(n=29)$} & \multicolumn{2}{|c|}{$\mathrm{IOP} \geq 26(n=7)$} & MD (95\% CI) & $p$ value* \\
\hline 1st day & $0.03 \pm 0.19$ & $0.00(0.00 ; 1.00)$ & $0.14 \pm 0.38$ & $0.00(0.00 ; 1.00)$ & $0.00(-0.01 ; 0.01)$ & 0.290 \\
\hline 7th day & $0.07 \pm 0.26$ & $0.00(0.00 ; 1.00)$ & $0.29 \pm 0.49$ & $0.00(0.00 ; 1.00)$ & $0.00(-0.01 ; 0.01)$ & 0.114 \\
\hline 1st month & $0.14 \pm 0.35$ & $0.00(0.00 ; 1.00)$ & $0.29 \pm 0.49$ & $0.00(0.00 ; 1.00)$ & $0.00(-0.01 ; 0.01)$ & 0.369 \\
\hline 24th month & $0.76 \pm 0.69$ & $1.00(0.00 ; 2.00)$ & $1.29 \pm 0.76$ & $1.00(0.00 ; 2.00)$ & $0.00(-1.00 ; 0.01)$ & 0.095 \\
\hline
\end{tabular}

IOP, intraocular pressure; MD, mean deviation. * Mann-Whitney U test; MD, difference in medians calculated as IOP washout $<26$ mm Hg group minus IOP washout $\geq 26$ group with $95 \%$ confidence interval.

spectively, at the end of the observation. Both groups differed significantly in baseline mean drug dose, $\mathrm{MD}=$ $-1.50,95 \%$ CI: $(-2.00 ;-1.00), p<0.001$. After surgery, the average amount of medication consumed differed between the 2 groups for each of the periods: 7 days, 1 month, 6 months, and 12 and 24 months after surgery with a lower level in the iStent IOP group $<26 \mathrm{~mm} \mathrm{Hg}$ (Table 6).

Prior to surgery, control patients with an IOP $<26 \mathrm{~mm}$ $\mathrm{Hg}$ took an average of $1.03 \pm 0.19$ drugs, while 24 months after surgery, the drug dose dropped to $0.76 \pm 0.69$. Patients from the control subgroup with IOP $\geq 26 \mathrm{~mm} \mathrm{Hg}$ received $1.86 \pm 0.69$ drugs and $1.29 \pm 0.76$ before the surgery and within 2 years after the surgery. Both subgroups of patients in the control group (IOP $\geq 26$ and IOP $<26$ $\mathrm{mm} \mathrm{Hg}$ ) differed significantly between each other in the average dose of drugs before surgery, $\mathrm{MD}=-1.00,95 \%$ CI: $(-1.00 ;-0.99), p<0.001$. On the other hand, during the 24-month observation period, statistically significant differences between the subgroups in the number of drugs taken at each observation point were not confirmed, as shown in Table 7.

\section{Safety}

Safety parameters involved observing BCVA, intraoperative complications, and postoperative adverse effects. There was an excellent safety profile seen for both groups with no cases of visual acuity deterioration or loss nor reports of any allergy or inflammation related to iStent in this study. Both groups were homogeneous with regard to the visual acuity; mean preoperative BCVA was $0.56 \pm$ 0.23 in the iStent group and $0.53 \pm 0.21$ in the control 
group, improving to $0.95 \pm 0.12$ and $0.94 \pm 0.13$ in both groups, respectively.

In the iStent group, patients with IOP $<26 \mathrm{~mm} \mathrm{Hg}$ had an average BCVA level before surgery of $0.49 \pm$ 0.22 , and 24 months after surgery, $0.95 \pm 0.11$. The corresponding BCVA level for the IOP $\geq 26 \mathrm{~mm} \mathrm{Hg}$ subgroup was $0.68 \pm 0.21$ before surgery and $0.91 \pm 0.17$ after 2 years of observation, respectively. The average BCVA level differed significantly between the 2 subgroups before surgery: $0.49 \pm 0.22$ versus. $0.68 \pm 0.21$, $\mathrm{MD}=-0.25,95 \% \mathrm{CI}:(-0.30 ;-0.07), p=0.008$, in favor of the IOP subgroup $<26 \mathrm{~mm} \mathrm{Hg}$. For the entire postoperative period, both iStent patient subgroups (IOP $\geq 26$ and IOP $<26$ ) did not differ significantly in terms of mean BCVA level.

In the control group for patients with IOP $<26 \mathrm{~mm} \mathrm{Hg}$, the average BCVA level before surgery was $0.52 \pm 0.23$ and 2 years after surgery, $0.94 \pm 0.13$. Patients with IOP $\geq 26 \mathrm{~mm} \mathrm{Hg}$ had a baseline BCVA level of $0.58 \pm 0.14$, and after 24 months of observation, it was $1.00 \pm 0.00$. There were no significant differences between the 2 subgroups of control patients for the entire follow-up period.

There were no significant differences in the safety profile between the 2 groups nor subgroups. No significant intraoperative complications were noted after iStent implantation with cataract surgery. In the immediate postoperative period for the iStent group, microhyphema was observed in the anterior chamber in 5 eyes, and 1 eye experienced a subconjunctival hemorrhage; all 6 cases spontaneously resolved within a week of surgery without sequelae. Complications unrelated to iStent implantation occurred over the course of long-term observation in 5 eyes. Four eyes developed posterior capsular opacification and were treated with $\mathrm{Nd}$ :YAG capsulotomy. One eye required intravitreal administration of an antiVEGF medication due to progression of age-related macular degeneration from dry to exudative form. Although this condition was a qualification exclusion criterion, this case was included because the AMD was diagnosed and subsequently progressed midway through the postoperative period. In the control group, corneal edema related to an increase in IOP was observed in 1 eye on postoperative day 1 , which resolved within 1 week. Viral corneal inflammation occurred in 1 eye from the control group at week 1 postoperative and was treated topically, resolving within 1 month with no visual complications. No eyes in either group required additional glaucoma surgery during the 24-month observation period.

\section{Discussion}

Our study confirmed the Battista's laboratory model assuming lower effectiveness of the hypotensive effect of iStent in IOP $\geq 26 \mathrm{~mm} \mathrm{Hg}$ caused by the collapse of the SC and a decrease in patency of distal aqueous humor outflow pathways from the anterior chamber of the eye. This effect is visible in the population effect and manifests as a decrease in IOP $\geq 20 \%$ compared to baseline in the group with initial IOP $<26 \mathrm{~mm} \mathrm{Hg}$ compared to cataract surgery alone 24 months after surgery (82.1. vs. 51.7, respectively, $p=0.024)$. This is also confirmed by the analysis of the amount of drugs taken, which showed a more favorable profile of the amount of reduction of antiglaucoma drugs in the iStent group $<26 \mathrm{~mm} \mathrm{Hg}$ compared to the iStent group $\geq 26 \mathrm{~mm} \mathrm{Hg}$ throughout the entire observation period $(0.07 \pm 0.26$ vs. $0.75 \pm 0.93, p=0.003,0.14 \pm 0.36$ vs. $0.88 \pm 1.02, p=0.005$, and $0.32 \pm 0.55$ vs. $0.88 \pm 1.26, p=$ 0.05 , during 6,12 , and 24 months after surgery, respectively).

This result can also explain results from other studies. Hann et al. [14] compared the number of collectors in enucleated healthy eyes and in POAG eyes, which were exposed to IOP at a level between 10 and $20 \mathrm{~mm} \mathrm{Hg}$. In healthy eyes, there are adaptive mechanisms that regulate the efficiency of the outflow tract in response to an increase in IOP. In the eyes with POAG, these mechanisms are disturbed. In response to an increase in IOP from 10 to $20 \mathrm{~mm} \mathrm{Hg}$, in healthy eyes, the total number of collectors increased (probably part of the collapsed collectors opens when the IOP is higher) by $26.6 \%$. In POAG's eyes, it also increased in the range of $10-20 \mathrm{~mm} \mathrm{Hg}$, but after exceeding $20 \mathrm{~mm} \mathrm{Hg}$, the number of closed collectors increased from 7.2 to $24.8 \%$ ( 4 times compared to their number in healthy eyes). In addition, in response to an increase in IOP in the eyes of POAG, the SC surface was reduced, which was caused by the depression of its inner wall in the CC holes and the reduction of the effective space for the flow of aqueous humor.

In our study, in the control group, we also observed a statistically significant decrease in the IOP value compared to the level before surgery (from $20.93 \pm 1.28$ to $17.79 \pm 2.50 \mathrm{~mm} \mathrm{Hg}$ in the IOP subgroup $<26 \mathrm{~mm} \mathrm{Hg}$ and from $26.00 \pm 0.00$ to $19.86 \pm 2.19$ in the subgroup $\geq 26 \mathrm{~mm}$ $\mathrm{Hg}$ ). According to various studies, the decrease in IOP after removal of the lens itself is on average $1.4-5.3 \mathrm{~mm}$ $\mathrm{Hg}$ [15-19]. Depending on the type of concomitant glaucoma, the largest is in the eyes with closed-angle glauco$\mathrm{ma}$ (PACG) and in pseudoexfoliative glaucoma (PXG). Various theories explaining this effect are considered. Af-

Ophthalmic Res 2021;64:327-336

333 
ter removal of the lens, the position of the choroidal and corneal-scleral trabecular lines changes, similar to the treatment with parasympathomimetics $[20,21]$. Other possible mechanisms are as follows:

1. Decrease in aqueous humor production due to vitreous pull by ciliary band fibers, caused by contraction of the lens capsule after cataract surgery [17].

2. Improvement of water flow through the trabecular and SC [20].

3. Improvement of uveoscleral outflow [22], caused by increased release of prostaglandins during the procedure: PGE-1 increases the outflow of aqueous humor by the conventional route, while PGF-2 by the alternative route [23].

In the case of PXG, the pseudoexfoliating material is washed out during the procedure from the anterior chamber, and especially from the angle of filtration, which facilitates the outflow of aqueous humor through the cleaned trabecular method. This hypothesis would also explain the subsequent gradual increase in IOP in this type of glaucoma - proportional to the reproduction and deposition of pseudoexfoliative deposits in the anterior segment of the eye. Analyzing the data from the above studies, it can also be seen that the decrease in IOP after surgery shows a strong inverse correlation with the preoperative depth of the anterior chamber, the width of the filtration angle, and the initial level of IOP. It can also be concluded that the hypotensive effect is most expressed during the first year after surgery [24] although there are single reports in the literature that a reduction in IOP is noted even after 10 years after surgery [25].

In our study, we had a homogeneous group of patients, consisting only of POAG cases, to exclude additional factors that may affect IOP after surgery (different rates of pseudoexfoliation deposition), but like other researchers, we also observed the lowest level of IOP in the control group after a year, with a slight increase in 24 months after surgery. Twenty-four months after the procedure, this effect decreases and no longer reaches statistically significant values, which may be caused by a gradual disappearance of the hypotensive effect of removing the lens and leaving only the IOP-lowering mechanism by improving the outflow due to the insertion of iStent.

Based on our study, it can be concluded that maintaining the target IOP in the iStent group $\geq 26 \mathrm{~mm} \mathrm{Hg}$ requires more $\mathrm{p} /$ glaucoma drugs compared to the iStent IOP $<26 \mathrm{~mm} \mathrm{Hg}$ group ( $0.07 \pm 0.26$ vs. $0.75 \pm 0.93, p=$ $0.003,0.14 \pm 0.36$ vs. $0.88 \pm 1.02, p=0.005$, and $0.32 \pm 0.55$ vs. $0.88 \pm 1.26, p=0.05$, in the 6 th, 12 th, and 24 th month of observation, respectively). In a similar study conducted by Ferguson et al. [10], the hypotensive effect of iStent was studied in groups with different initial IOP, and the level of drugs before surgery in patients with IOP $>24 \mathrm{~mm}$ $\mathrm{Hg}$ was 2.00, and 24 months after surgery, 1.33 (decrease by $34 \%$ ), while in in the $22-24 \mathrm{~mm}$ Hg group, the decrease was $67 \%$. Their study confirms that the decrease in the amount of drugs after surgery is much smaller in the group with high IOP values.

Interestingly, in the control group, during the 24-month follow-up period, no statistically significant differences between IOP $<26$ and $\geq 26 \mathrm{~mm} \mathrm{Hg}$ subgroups in the number of medications taken at any observation point were confirmed, which may support the hypothesis of different mechanisms of hypotensive action in these 2 types of surgery. As is known, the cataract surgery itself also allows the reduction of antiglaucoma drugs. In our previous studies, it was $34 \%$ of all patients with glaucoma (1.7 and after surgery fell to 1.22): $20.8 \%$ of patients in the POAG group, $37.5 \%$ of patients in the group with secondary PXG, and in as many as $41.7 \%$ of patients with PACG group [26]. In the study of Samuelson et al. [13], it was 15\% from baseline, and in the study by Malvankar-Mehta et al. [27], it fell from 1.33 before surgery to 1.01 .

Our results indicate a highly acceptable safety profile, with the safety profile in the iStent group similar to cataract surgery alone. There were no significant adverse events or long-term complications related to iStent, and no vision loss was observed in any eye. Mean visual acuity was significantly improved in the majority of cases. Titanium iStent is highly biocompatible, and there were no reports of inflammation or allergy to the device based on the safety profile observed. Indeed, in the years since the iStent approval and its consequently wide global usage across different populations, there have been no reports of device allergy in the currently available literature. In the iStent $\geq 26 \mathrm{~mm} \mathrm{Hg}$ group, BCVA was lower before the surgery $(0.49 \pm 0.22$ vs. $0.68 \pm 0.21, \mathrm{MD}=-0.25,95 \% \mathrm{CI}$ : $(-0.30 ;-0.07), p=0.008)$, which confirms the role of the lens in the generation of high IOP due to the development of cataracts and its swelling.

This study has some obvious strengths. To the best of our knowledge, this is the first study comparing the antihypertensive efficacy of microbypass and cataract surgery alone with the initial IOP criterion $<26$ and $\geq 26 \mathrm{~mm} \mathrm{Hg}$. Furthermore, it is the first report of iStent as a treatment for glaucoma in the Polish population. We performed a randomized controlled trial with allocation concealment. All surgeries were performed in 1 place, by a single, highly experienced surgeon, on a demographically homoge- 
neous group of patients qualified for inclusion into the study. Postoperatively, we were able to perform a direct comparison between the effect of phacoemulsification alone compared to iStent implantation in combination with phacoemulsification on IOP and medication burden reduction depending on initial IOP.

This study is not without limitations. Baseline characteristics were generally balanced. However, preoperative medication burden was slightly different between the 2 groups, despite randomization. We experienced an element of attrition bias, resulting in an unequal sample size between the 2 groups after randomization. Once randomized, a proportion of patients in the control group returned to their local ophthalmologist for follow-up, while those randomized to the iStent group remained under the care of the investigating site. Despite these limitations, we believe the study is relevant in providing evidence for safety and performance of both surgeries.

\section{Conclusion}

An important stage in the qualification for iStent implantation should be the assessment of patency of distal outflow tracts since the probability of success is then greatest. We should be guided not only by the degree of advancement of glaucoma visible in the field of vision test, which is an indirect exponent of the outflow of aqueous humor from the eye, but also the level of preoperative IOP. The conclusions of the presented studies are of great practical value because they provide an explanation of why the effectiveness of the iStent microbypass may be limited in eyes with chronically high IOP. In the case of cataract surgery, the antihypertensive effect has a different mechanism than in the group subjected to phacoemulsification with simultaneous iStent implantation, and therefore the preoperative level of IOP in the control group before surgery does not affect the level of IOP achieved after surgery. In the case of a group of treatments combined with the use of iStent, where the hypotensive mechanism is additionally based on lowering the resistance at the level of the inner wall of the SC, the additive mechanism of these 2 treatments works. In this group, the initial IOP level is important: in the $<26 \mathrm{~mm}$ subgroup, IOP reduction will be stable and possible using the least amount of antiglaucoma drugs, and the mechanism of action will be based on improving the outflow through the pulmonary gland. In the IOP $\geq 26 \mathrm{~mm} \mathrm{Hg}$ subgroup, where the distal pathways of the aqueous hu- mor outflow are obstructed, the hypotensive mechanism mainly depends on the removal of the lens, so IOP tends to increase 1 year after surgery and requires more drugs. Therefore, when qualifying a patient with IOP above 26 $\mathrm{mm} \mathrm{Hg}$ intolerant to antiglaucoma drugs, it is reasonable to choose a procedure with a different mechanism of action.

The laboratory models proposed by Battiste and Hann are highly likely. However, further research is needed on a larger population group and with a longer observation period. Perhaps, defining precisely the target group of patients would result in even better hypotensive effectiveness of these treatments.

\section{Statement of Ethics}

The trial protocol was conducted in accordance with the tenets of the Helsinki Declaration and was approved by the Bioethics Committee at the Military Institute of Medicine (No. 16/ WIM/2013). Written legally binding, conscious informed consent was obtained from every patient prior to their recruitment in the trial.

\section{Conflict of Interest Statement}

The authors have no commercial or proprietary interest in any of the products or companies mentioned in this article.

\section{Funding Sources}

The authors did not receive any funding.

\section{Author Contributions}

Substantial contributions to the conception or design of the work and the acquisition, analysis, or interpretation of data for the work: Milena Kozera, MD; Joanna Konopińska, MD, PhD; Prof. Zofia Mariak, MD, PhD; and Prof. Marek Rękas, MD, PhD. Drafting the work or revising it critically for important intellectual content: Milena Kozera, MD; Joanna Konopińska, MD, PhD. Agreement to be accountable for all aspects of the work in ensuring that questions related to the accuracy or integrity of any part of the work are appropriately investigated and resolved: Prof. Zofia Mariak, MD, PhD. Final approval of the version to be published: Prof. Marek Rękas, MD, PhD. 


\section{References}

1 Soltau JB, Rothman RF, Budenz DL, Greenfield DS, Feuer W, Liebmann JM, et al. Risk factors for glaucoma filtering bleb infections. Arch Ophthalmol. 2000;118(3):338-42.

2 Gedde SJ, Schiffman JC, Feuer WJ, Herndon LW, Brandt JD, Budenz DL. Treatment outcomes in the Tube Versus Trabeculectomy (TVT) study after five years of follow-up. Am J Ophthalmol. 2012;153(5):789-e2.

3 Wang K, Read AT, Sulchek T, Ethier CR. Trabecular meshwork stiffness in glaucoma. Exp Eye Res. 2017;158:3-12.

4 Dautriche CN, Tian Y, Xie Y, Sharfstein ST. A closer look at Schlemm's canal cell physiology: implications for biomimetics. J Funct Biomater. 2015;6(3):963-85.

5 Hann CR, Vercnocke AJ, Bentley MD, Jorgensen SM, Fautsch MP. Anatomic changes in Schlemm's canal and collector channels in normal and primary open-angle glaucoma eyes using low and high perfusion pressures. Invest Ophthalmol Vis Sci. 2014;55(9):583441.

6 Saheb H, Ahmed II. Micro-invasive glaucoma surgery: current perspectives and future directions. Curr Opin Ophthalmol. 2012;23(2): 96-104.

7 Battista SA, Lu Z, Hofmann S, Freddo T, Overby DR, Gong H. Reduction of the available area for aqueous humor outflow and increase in meshwork herniations into collector channels following acute IOP elevation in bovine eyes. Invest Ophthalmol Vis Sci. 2008; 49(12):5346-52.

8 Dvorak-Theobald G. Further studies on the canal of Schlemm; its anastomoses and anatomic relations. Am J Ophthalmol. 1955;39(4 Pt 2):65-89.

9 Craven ER, Katz LJ, Wells JM, Giamporcaro JE. Cataract surgery with trabecular microbypass stent implantation in patients with mild-to-moderate open-angle glaucoma and cataract: two-year follow-up. J Cataract Refract Surg. 2012;38(8):1339-45.

10 Ferguson TJ, Berdahl JP, Schweitzer JA, Sudhagoni RG. Clinical evaluation of a trabecular microbypass stent with phacoemulsification in patients with open-angle glaucoma and cataract. Clin Ophthalmol. 2016;10:1767-73.
11 Fea AM, Consolandi G, Zola M, Pignata G, Cannizzo P, Lavia C, et al. Micro-bypass implantation for primary open-angle glaucoma combined with phacoemulsification: 4-year follow-up. J Ophthalmol. 2015 Oct 26;2015: 795357.

12 Neuhann TH, Hornbeak DM, Neuhann RT, Giamporcaro JE. Effectiveness and safety of trabecular microbypass stent implantation with cataract surgery in patients with glaucoma or ocular hypertension: five-year outcomes. J Cataract Refract Surg. 2019;45(3): 312-20.

13 Samuelson TW, Katz LJ, Wells JM, Duh YJ, Giamporcaro JE. Randomized evaluation of the trabecular micro-bypass stent with phacoemulsification in patients with glaucoma and cataract. Ophthalmology. 2011;118(3):45967.

14 Grieshaber MC, Pienaar A, Olivier J, Stegmann R. Clinical evaluation of the aqueous outflow system in primary open-angle glaucoma for canaloplasty. Invest Ophthalmol Vis Sci. 2010;51(3): 1498-504.

15 Hayashi K, Hayashi H, Nakao F, Hayashi F. Changes in anterior chamber angle width and depth after intraocular lens implantation in eyes with glaucoma. Ophthalmology. 2000; 107(4):698-703.

16 Damji KF, Konstas AG, Liebmann JM, Hodge WG, Ziakas NG, Giannikakis S, et al. Intraocular pressure following phacoemulsification in patients with and without exfoliation syndrome: a 2 year prospective study. Br J Ophthalmol. 2006;90(8):1014-8.

17 Suzuki R, Tanaka K, Sagara T, Fujiwara N. Reduction of intraocular pressure after phacoemulsification and aspiration with intraocular lens implantation. Ophthalmologica. 1994;208(5):254-8.

18 Suzuki R, Kuroki S, Fujiwara N. Ten-year follow-up of intraocular pressure after phacoemulsification and aspiration with intraocular lens implantation performed by the same surgeon. Ophthalmologica. 1997;211(2):7983.
19 Cekiç O, Batman C. The relationship between capsulorhexis size and anterior chamber depth relation. Ophthalmic Surg Lasers. 1999; 30(3):185-90.

20 Hayashi K, Hayashi H, Nakao F, Hayashi F. Effect of cataract surgery on intraocular pressure control in glaucoma patients. J Cataract Refract Surg. 2001;27(11):1779-86.

21 Stawowski Ł, Konopińska J, Deniziak M, Saeed E, Zalewska R, Mariak Z. Comparison of ExPress mini-device implantation alone or combined with phacoemulsification for the treatment of open-angle glaucoma. J Ophthalmol. 2015;2015:613280.

22 Link S, Häring G, Hedderich J. Effect of phacoemulsification and posterior chamber lens implantation on intraocular pressure in patients with and without open-angle glaucoma. Ophthalmologe. 2000;97(6):402-6.

23 Tarongoy P, Ho CL, Walton DS. Angle-closure glaucoma: the role of the lens in the pathogenesis, prevention, and treatment. Surv Ophthalmol. 2009;54(2):211-25.

24 Mansberger SL, Gordon MO, Jampel H, Bhorade $\mathrm{A}$, Brandt JD, Wilson $\mathrm{B}$, et al. Reduction in intraocular pressure after cataract extraction: the Ocular Hypertension Treatment Study. Ophthalmology. 2012;119(9):182631.

25 Shingleton BJ, Gamell LS, O’Donoghue MW, Baylus SL, King R. Long-term changes in intraocular pressure after clear corneal phacoemulsification: normal patients versus glaucoma suspect and glaucoma patients. J Cataract Refract Surg. 1999;25(7):885-90.

26 Konopińska J, Mariak Z. Wpływ fakoemulsyfikacji zaćmy na głębokość komory przedniej i szerokość kąta przesączania $\mathrm{w}$ oczach $\mathrm{z}$ jaskrą- wyniki wstępne. Okulistyka. 2010;3: 115-9.

27 Malvankar-Mehta MS, Iordanous Y, Chen YN, Wang WW, Patel SS, Costella J, et al. iStent with phacoemulsification versus phacoemulsification alone for patients with glaucoma and cataract: a meta-analysis. PLoS One. 2015;10(7):e0131770. 